\title{
Analysis of FMR1 (CGG) $n$ alleles and FRAXA microsatellite haplotypes in the population of Greenland: implications for the population of the New World from Asia
}

\author{
Lars Allan Larsen ${ }^{1}$, Judith SM Armstrong ${ }^{2}$, Karen Grønskov ${ }^{2}$, Helle Hjalgrim ${ }^{2}$, \\ Karen Brøndum-Nielsen ${ }^{2}$, Lis Hasholt ${ }^{3}$, Bent Nørgaard-Pedersen ${ }^{1}$ and Jens Vuust ${ }^{1}$ \\ ${ }^{1}$ Department of Clinical Biochemistry, Statens Serum Institut, Copenhagen \\ ${ }^{2}$ Department of Medical Genetics, The John F Kennedy Institute, Glostrup, Denmark \\ ${ }^{3}$ Institute of Medical Biochemistry and Genetics, University of Copenhagen, The Panum Institute, Copenhagen, \\ Denmark
}

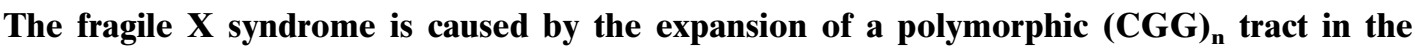
promoter region of the FMR1 gene. Apparently the incidence of fragile $\mathrm{X}$ syndrome is rare in the population of Greenland. In order to examine population-related factors involved in stability of the (CGG) $)_{n}$ sequence, DNA samples obtained randomly from the Greenlandic population were analysed for size and AGG interspersion pattern of the FMR1 (CGG) ${ }_{n}$ region and associated DXS548-FRAXAC1 haplotypes. In addition a large Greenland family with unstable transmission in the premutation range was analysed. The (CGG) ${ }_{n}$ allele sizes in the Greenland population showed a narrow distribution similar to that reported for Asian populations. DNA sequencing of alleles with 36 CGG repeats revealed an AGG(CGG)6 insertion previously reported exclusively in Asian populations and a high frequency of alleles

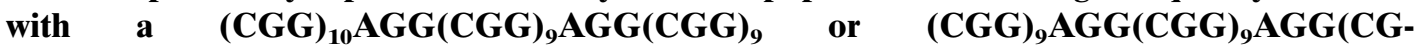
G) ${ }_{6} \mathrm{AGG}(\mathrm{CGG})_{9}$ sequence pattern was found. Thus the data confirm the Asian origin of the Greenlandic (Eskimo) population and indicates that some (CGG) alleles have remained stable for 15-30,000 years, since the population of the New World arrived from Asia via the Bering Strait.
\end{abstract}

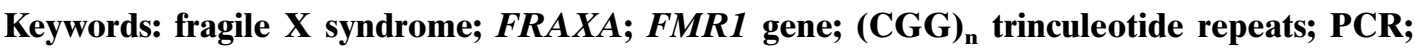
Eskimo

\section{Introduction}

Fragile $\mathrm{X}$ syndrome is the most common form of inherited mental retardation, with an incidence of 1 in 4-5000 males. ${ }^{1,2}$ The condition is usually caused by

Correspondence: Lars Allan Larsen MSc, Department of Clinical Biochemistry, Statens Serum Institut, Artillerivej 5, DK-2300 Copenhagen S, Denmark. Tel: + 45326836 55; Fax: +45 326838 78; E-mail: lal@ssi.dk

Received 24 February 1999; revised 4 June 1999; accepted 11 June 1999 expansion of an unstable $(\mathrm{CGG})_{\mathrm{n}}$ trinucleotide repeat sequence in the promoter region in the FMRl gene (Xq27.3), leading to hypermethylation of a neighbouring $\mathrm{CpG}$ island and repression of FMR1 mRNA transcription. ${ }^{3-5}$ In normal individuals, the region is stably transmitted but polymorphic, with CGG repeats ranging in number from 5 to 52 . In carriers of the unstable premutation, repeat lengths of 50-200 CGG are usually found and in affected individuals a full mutation of $>200$ repeats can be found. ${ }^{6}$ Little is known about the factors involved in stabilising the 
$(\mathrm{CGG})_{\mathrm{n}}$ tract in the normal population. Analyses of microsatellites located around the FMR1 gene have demonstrated linkage for haplotypes associated with the disease. ${ }^{7}$ Sequence analysis of $(\mathrm{CGG})_{\mathrm{n}}$ alleles have shown that a large proportion of normal alleles are interrupted by an AGG triplet for each 9-10 CGG. However, analysis of normal alleles associated with haplotypes overrepresented among fragile $\mathrm{X}$ patients, led to the hypothesis that alleles with a tract of $>24$ pure CGG repeats are predisposed to repeat expansion. ${ }^{8}$ Several other studies have confirmed that long stretches of pure CGG repeats are associated with instability of the FMR1 (CGG) repeat. $^{9-12}$

Studies of $(\mathrm{CGG})_{\mathrm{n}}$ repeat structures in selected human populations have shown a high degree of conservation of the canonical (CGG) ${ }_{9} \mathrm{AGG}$ interruption pattern in different populations and have confirmed the proposed stabilising effect of AGG interruptions. $^{13,14}$ We have studied FMR1 (CGG) sequence patterns and DXS548-FRAXAC1 haplotypes in the population of Greenland in order to examine molecular factors influencing the stability of the human FMR1 gene. We also present a large Greenland family segregating an unstable premutation in combination with a rare FRAXA microsatellite haplotype.

\section{Materials and Methods}

\section{DNA Sample Material}

Blood spots on filter paper, used for newborn screening of the Danish (Caucasian) and Greenlandic (Eskimo) population, were used as sample material. The population of Greenland originates from the Eskimo-Aleut population, which is believed to have migrated to North America ('The New World') from North-East Asia across a land bridge, formed at the Bering strait, in the late Paleolithic period 15-30,000 years ago. ${ }^{15}$ The present population of Greenland is approximately 56,000 , with a newborn population of 1,100 . The uptake of the PKU screening is approximately $80 \%$. The study was totally anonymous and the samples were taken randomly from a pool of daily routine samples. DNA was extracted from $3 \mathrm{~mm}$ filter paper discs as described. ${ }^{16}$ The project is in agreement with the Helsinki declaration II, and has been approved by the local Science Ethics Committee, J No (KF) 01-182/96.

\section{PCR Amplification of FRAXA Microsatellites}

PCR amplification of $F M R 1(\mathrm{CGG})_{\mathrm{n}}$ repeats was performed essentially as described ${ }^{16}$ using fluorescently labelled primers. DXS548 and FRAXAC1 microsatellites were amplified by multiplex PCR using primers labelled with FAM or TET fluorescent dyes (Perkin Elmer, Foster City, CA). Published primer sequences were used. ${ }^{5,17}$ Thermal cycling was performed in a PTC200 'DNA engine' (MJ Research, Waltham, MA), with the temperature profile: $95^{\circ} \mathrm{C}$ for $2 \mathrm{~min}$ followed by 31 cycles of $95^{\circ} \mathrm{C}$ for $20 \mathrm{~s}, 62^{\circ} \mathrm{C}$ for $30 \mathrm{~s}, 55^{\circ} \mathrm{C}$ for $30 \mathrm{~s}$ and $72^{\circ} \mathrm{C}$ for $1 \mathrm{~min}$, ending with a $7 \mathrm{~min}$ extension at $72^{\circ} \mathrm{C}$.

\section{DNA Sequencing}

Purified PCR products were sequenced with a TaqFS DyeDeoxy $^{\mathrm{TM}}$ Terminator Cycle Sequencing kit (Perkin Elmer, Foster City, CA) according to the manufacturer's instructions, using the internal sequencing primers 5'CGTGGTTTCAGTGTTTAC $3^{\prime}$ (forward) and $5^{\prime}$ CTCCTCCATCTTCTCTTC 3' (reverse). All sequences were analysed using an ABI373 DNA sequencer (Perkin Elmer, Foster City, CA).

\section{Greenland Family with Unstable CGG Repeat:} Ascertainment and Investigation

From our clinical diagnostic service we have identified one large family from Greenland with an unstable CGG repeat at the FRAXA locus, which segregated in four generations in 16 individuals, apparently without expanding to a full mutation.

The family was ascertained through IV-2 and IV-3. IV-2, the oldest of the two index brothers, is 6 years old. He is mildly psychomotorically delayed with no dysmorphic features or physical abnormalities. His language development has been delayed as well as his social skills. His mood is stable. IV-3, 5 years old, is the more severely affected of the two brothers, as he shows clear autistic features with hyperactive behaviour, perseveration, no expressive language and severe mood changes with temper tantrums. His general development is delayed. He has no dysmorphic features or physical abnormalities.

The repeat size was determined according to ref. 6 . Interspersion analysis in premutation male carriers was done according to ref. 12. Haplotype analysis with PCR amplification of the microsatellites DXS548, FRAXAC1 and FRAXAC2 was done both as described under 'PCR amplification of FRAXA microsatellites' for two of the microsatellites, and with a radioactive method as described elsewhere. ${ }^{18}$ Western blot analysis was performed as described elsewhere. ${ }^{18}$ Analysis for FRAXE expansion was performed with standard Southern blot technique using the OxE18 probe on EcoRI blots and HindIII blots. ${ }^{19}$

\section{Results}

\section{Distribution of (CGG) Alleles and DXS548-FRAXAC1 Haplotypes in the Greenland Population}

PCR analysis of FMR1 (CGG) $)_{n}$ alleles in DNA extracted from 101 newborn males sampled randomly from the Greenland population showed a distribution with two major peaks around 30 CGG $(53 \%$ with 29-31 CGG) and 36CGG (26\% with 35-37CGG). Only $8 \%$ of the alleles had fewer than 26 repeats (Figure 1). This is very similar to distributions reported for Asian populations. ${ }^{20-22}$

Comparison of $(\mathrm{CGG})_{\mathrm{n}}$ allele sizes and linked DXS548-FRAXAC1 haplotypes showed that $85 \%$ of alleles with 29-31 CGG were linked to haplotype 7-3 
and $88 \%$ of alleles with $35-37$ CGG were linked to haplotype 6-4 (Figure 1).

\section{Sequencing of FMR1 (CGG) in Greenlandic Males}

The $(\mathrm{CGG})_{\mathrm{n}}$ sequence was determined for 85 DNA samples extracted from Greenlandic males by direct sequencing of PCR products. Twenty-three male alleles in the range of $19-44 \mathrm{CGG}$ in repeat size were not sequenced due to shortage of sample material. The sequenced alleles are classified with respect to DXS548-FRAXAC1 haplotypes in Figure 2.

The sequenced alleles are generally highly interrupted by AGG triplets, with $92 \%$ of the alleles having two or three AGG interruptions. Most of the (CGG) alleles analysed, had a sequence organisation of $(\mathrm{CGG})_{10} \mathrm{AGG}(\mathrm{CGG})_{9} \mathrm{AGG}(\mathrm{CGG})_{9}$ (Figure 2). The DNA sequencing also revealed a (CGG) ${ }_{6}$ AGG insertion in $20 \%(17 / 85)$ of the samples (Figure 2). This insertion has previously been described exclusively in the Asian population, ${ }^{20,23}$ thus our data support the theory of an Asian origin of the Eskimo component of the Greenland population. ${ }^{15}$

\section{Greenlandic family: Haplotype Analysis, AGG Interspersion Analysis and Segregation of Premutation}

Blood samples from 18 family members were investigated for the fragile $\mathrm{X}$ syndrome by Southern blot and PCR analyses. Sixteen samples showed expansion of the CGG repeat ranging in size from 57 to 70 (Figure 3a and $b$ ).

The premutation was shown to originate in $\mathrm{I}-1$, who fathered eight obligate carrier daughters. In four of these, the repeat expanded by one or a few repeats; in two there was a stable transmission, and in two a regression by one or two repeats. In the following generation a further slight expansion occurred in those investigated, and in the youngest generation (IV) the two brothers showed increases in repeats to 70 and 67 CGG (Figure $3 a$ and $b$ ).

To exclude possible mosaicism in the two index brothers we investigated skin biopsies from both and found expansions to be of the same size without evidence of a full mutation. Western blot analysis on protein extracts from skin fibroblasts likewise indicated the presence of FMRP protein (data not shown). Point

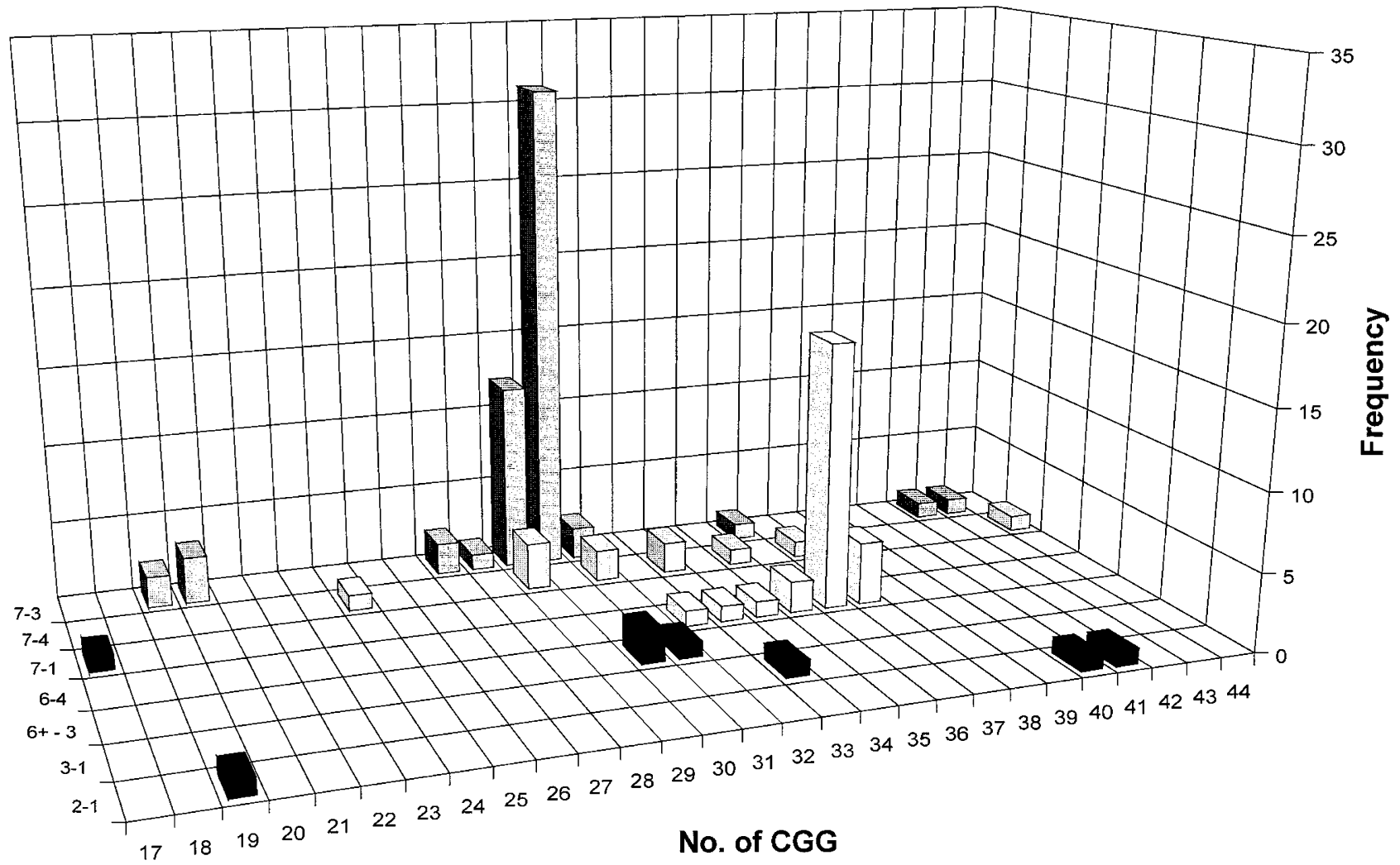

Figure 1 Distribution of FMR1 $(C G G)_{n}$ repeats and DXS548-FRAXAC1 haplotypes in the Greenland population. The nomenclature of the haplotypes is according to Macpherson et al. ${ }^{34}$ 


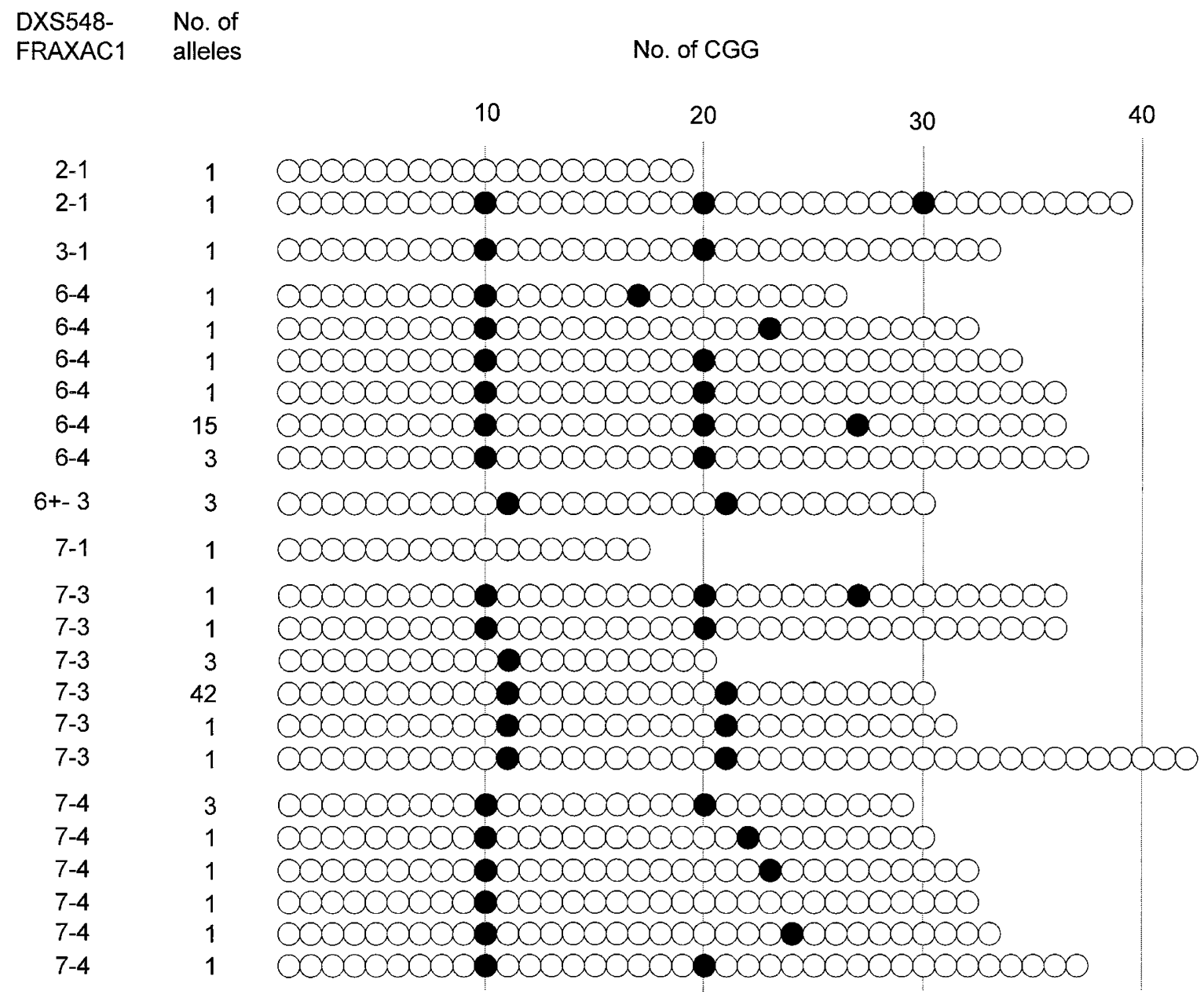

Figure 2 AGG interspersion pattern of 85 sequenced FMR1 $(C G G)_{n}$ alleles from Greenland males. The alleles are classified according to the associated DXS548-FRAXAC1 haplotype (first column). Only one of each allele type is shown, and the number of each allele type is indicated in the second column. The AGG interspersion patterns are shown from the $5^{\prime}$ to the $3^{\prime}$ end. Open circles represent CGG triplets; solid circles represent AGG triplets. The number of triplets are indicated on top

mutations in FMR1 was ruled out in IV-2 by SSCP analysis $^{24}$ and FRAXE was ruled out by Southern blotting.

AGG interspersion analysis was carried out in four premutated males. All four samples showed a sequence pattern of $(\mathrm{CGG})_{9} \mathrm{AGG}(\mathrm{CGG})_{\mathrm{n}}$, with $n$ ranging from 49 to 57 CGG (data not shown). Haplotype analysis showed the premutation carriers to possess the haplotype $2-4-6^{+}$for markers DXS548, FRAXAC1 and FRAXAC2.

\section{Discussion}

The distribution of FMR1 (CGG) $)_{n}$ alleles is considerably different in Caucasian and Asian populations. $^{6,20-22}$ Analysis of the CGG distribution in the
Greenland population (Figure 1) showed similarities to the distribution in Asian populations, with a high frequency of 35-37CGG and a lower frequency of alleles ranging from 20-23 CGG in size, compared with Caucasian populations. Although similarities to Asian distributions were significant, minor deviations were observed. The major difference is that the modal repeat length of Asian populations is $28-29$ CGG repeats, whilst $30 \mathrm{CGG}$ repeats is the modal repeat length in the Greenlandic population (Figure 1). Sequencing of the $(\mathrm{CGG})_{\mathrm{n}}$ alleles and analysis of associated DXS548FRAXAC1 haplotypes showed that the most frequent occuring $(\mathrm{CGG})_{\mathrm{n}}$ allele in the Greenlandic population has a sequence organisation of (CGG) $)_{10} \mathrm{AGG}(\mathrm{CG}-$ $\mathrm{G})_{9} \mathrm{AGG}(\mathrm{CGG})_{9}$, and is associated with haplotype 7-3 (Figure 2). These alleles are typically Caucasian, whilst Asian modal alleles have the sequence organisation of 


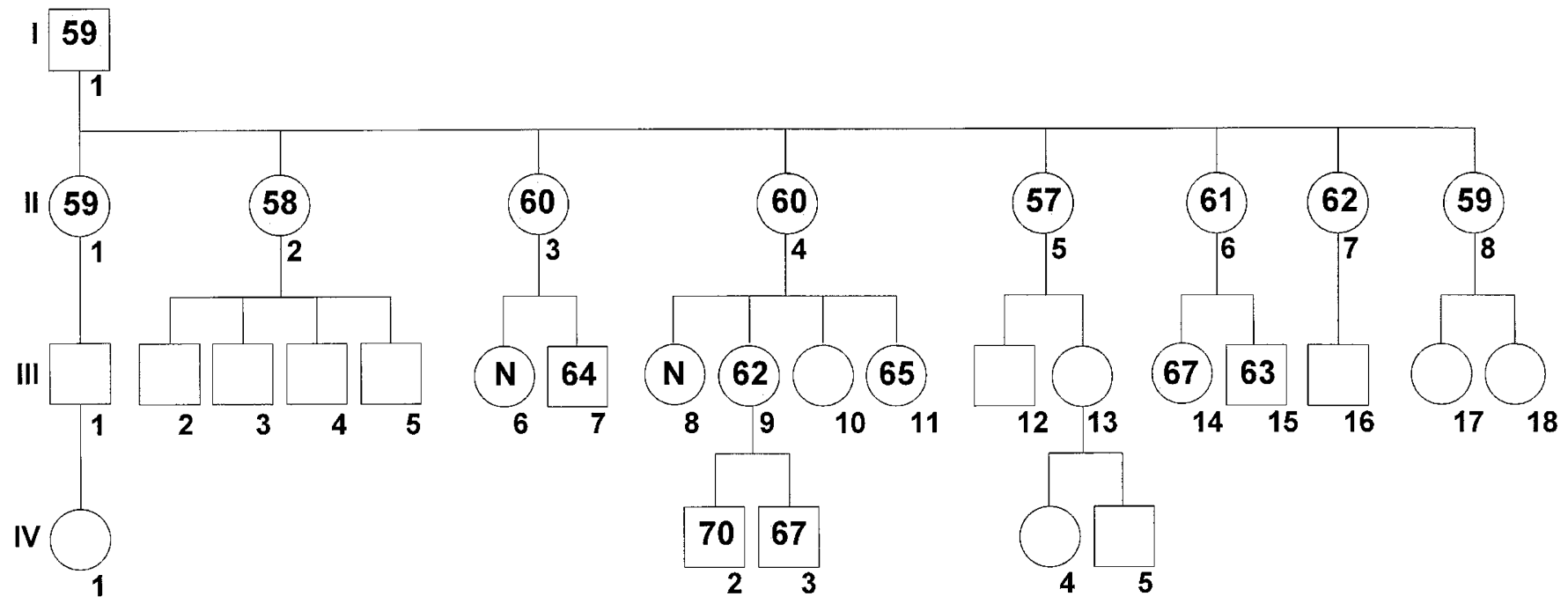

Figure 3a Pedigree of a Greenland family. Shaded symbols refer to premutated individuals, the numbers inside the symbols refer to repeat number. All premutated individuals except III-14 were analysed in the same experiment to make size determination more accurate (see Figure $3 b$ ). $N$ refers to a normal individual. Empty symbols refer to subjects not investigated

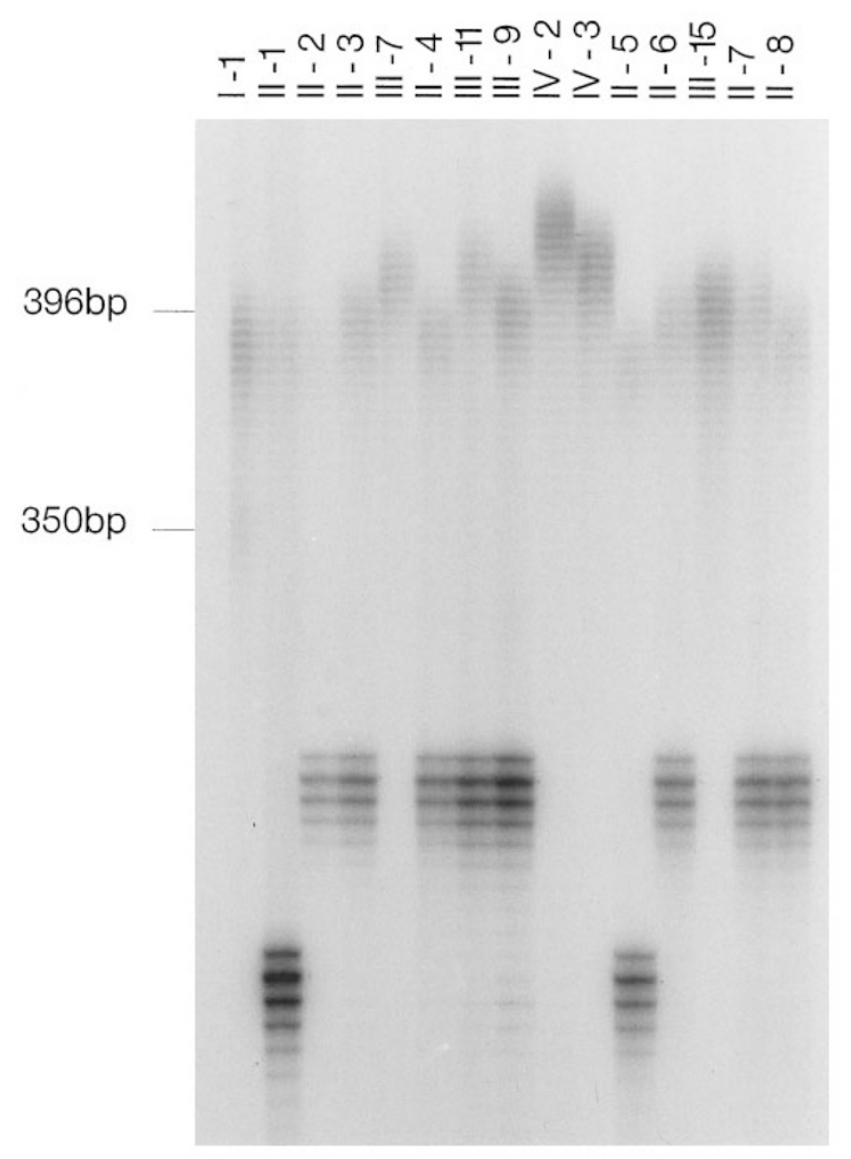

Figure 3b PCR amplification of CGG repeat in the Greenland family, showing the instability of the repeat
$(\mathrm{CGG})_{9} \mathrm{AGG}(\mathrm{CGG})_{9} \mathrm{AGG}(\mathrm{CGG})_{9}$ and are normally associated with haplotype $7-4 .^{20,22}$

Alleles with 36CGG repeats in the Greenlandic population were mainly associated with haplotype 6-4 (Figure 2). This is also different from Asian populations in which these alleles were found to associate with haplotype $7-4{ }^{20,22}$

However, both $(\mathrm{CGG})_{29}$ alleles associated with haplotype 7-3 and $(\mathrm{CGG})_{36}$ alleles associated with haplotype 6-4 exist in Asian populations; ${ }^{14,22}$ thus the changed frequency of these haplotypes from the Asian to the Greenland population may reflect random genetic drift due to the relative small population sizes believed to exist in the late Paleolithic era. ${ }^{15}$ It may also be caused by genetic mixture with the Danish population, which has been in contact with the Eskimo population since $1721 .^{25}$ Studies dealing with the frequency of Caucasian genes in the Greenland gene pool indicate that this frequency may be as high as $25 \%$ in most parts of the population. ${ }^{26,27}$ However, a more systematic study of this problem is certainly needed.

Furthermore, the uptake of newborn screening in Greenland is only $80 \%$. This may partly be due to a particularly low uptake in isolated communities. The genetic mixture of Eskimo and Caucasian genes is presumably low in such isolated communities, thus our sample material may be slightly biased towards samples with Caucasian mixture.

The existence of a (CGG) ${ }_{6} \mathrm{AGG}$ insertion, previously described exclusively in Asian populations, ${ }^{20,23}$ in a large proportion of the Greenland $(\mathrm{CGG})_{\mathrm{n}}$ alleles 
studied here, confirms an Asian origin of the Greenlandic population, and adds new evidence for the 'out of Asia' theory of the colonisation of the New World 15-30,000 years ago. ${ }^{15}$ The (CGG) repeats in native Americans have been studied by several groups, ${ }^{13,14,20}$ but none of these studies have found the (CGG) ${ }_{6} \mathrm{AGG}$ insertion in native Americans. This may be due to the relatively small sample sizes in these studies, but may also be caused either by a later migration of the Eskimo population compared with the Amerind and the Na-dene populations, as proposed in the 'three migrations-theory ${ }^{28}$ or by genetic bottlenecks during the population of the New World. ${ }^{29}$

DNA sequencing of the FMR1 (CGG) alleles showed a high proportion of AGG interruptions in the CGG repeat structure, with $92 \%$ of the alleles having two or more AGG interruptions (Figure 2). A high proportion of the alleles had the sequence organisation $(\mathrm{CGG})_{10} \mathrm{AGG}(\mathrm{CGG})_{9} \mathrm{AGG}(\mathrm{CGG})_{9} \quad(49 \%) \quad$ and $(\mathrm{CGG})_{9} \mathrm{AGG}(\mathrm{CGG})_{9} \mathrm{AGG}(\mathrm{CGG})_{6} \mathrm{AGG}(\mathrm{CGG})_{9}$ $(18 \%)$. These sequence organisations have been found in most $30 \mathrm{CGG}$ and $36 \mathrm{CGG}$ alleles analysed worldwide and in Asia, respectively, indicating that these alleles have remained stable since they were separated from the rest of the world by the Bering Strait dispersal 15,000 years ago. Thus, the data are in agreement with the hypothesis, that AGG interruptions have a stabilising effect on (CGG) $)_{n}$ alleles. The longest pure CGG block among the normal Greenlandic alleles was 21 CGG repeats (Figure 2). Analysis of FMR1 alleles in both Caucasian and Asian populations has led to the hypothesis that a proportion of the normal alleles may be unstable, predisposed to mutate to the fragile $\mathrm{X}$ full mutation. ${ }^{8,30}$ In Caucasian populations these predisposed alleles would have long blocks of uninterrupted ( $>24$ ) repeats. $^{8}$ The absence of alleles with $>24$ pure CGGs (Figure 2) in the Greenland population could indicate that most of the predisposed alleles may have been absent from the pool of founder chromosomes or were lost by genetic drift. It is interesting to note that the haplotype 6-4 (DXS548-FRAXAC1), occurs at a relatively high frequency in this population $(25 \%)$. This is known in Caucasian populations to be the most frequent haplotype in the fragile $\mathrm{X}$ patient population. It is noteworthy that in the Greenlandic population, the 6-4 haplotype was mostly found in association with the $(\mathrm{CGG})_{9} \mathrm{AGG}(\mathrm{CGG})_{9} \mathrm{AGG}(\mathrm{CGG})_{6} \mathrm{AGG}(\mathrm{CGG})_{9}$ allele, which is also found in Asian populations. However, comparing the frequency of fragile $\mathrm{X}$ syndrome in Asian and Caucasian population did not reveal differences, ${ }^{31}$ although the 6-4 haplotype is twice as frequent in Asian populations. Furthermore, AGG interspersion analysis has shown the haplotype 6-4 in the normal Caucasian population to be associated with a different CGG/AGG pattern, containing an intermediate block of 11 to $12 \mathrm{CGG}$ repeats. ${ }^{10}$ This indicates, that risk haplotypes are not the same in different populations, and extrapolations cannot be made.

Data from the family presented show that an unstable premutated CGG repeat does occur in the Greenlandic population, although so far no full mutation has been demonstrated. However, only few patients have been investigated so far. The ascertainment of the family occurred through two young boys with deviant behaviour and development. We assume that the association of the abnormal phenotype with the premutation could be fortuitous, although there have been indications in the literature of a potential phenotypic effect of a premutation, as evidenced by premature ovarian failure in females ${ }^{32,33}$ and an overrepresentation of intermediate alleles (41-60 CGG) in mentally retarded male populations. ${ }^{1}$

It is interesting to note that, although there is an overall tendency towards expansion, no expansion to full mutation occurred in the seven maternal transmissions studied in this family. These results confirm both that pure repeat lengths above $34 \mathrm{CGG}$ may be unstable $^{12}$ and that premutations of $<70$ CGG repeats in size seldom expand to full mutations. ${ }^{6}$

The haplotype (DXS548-FRAXAC12-4) segregating with this repeat was not otherwise found in the Greenlandic population sample investigated, but has been found in the Danish (unpublished observations) as well as in other Caucasian populations. It appears to be a rare 'risk' haplotype for the fragile $\mathrm{X}$ syndrome in the Danish population.

\section{Acknowledgements}

We would like to thank Dr Anna Murray for help and guidance of the AGG interspersion analysis and Dr Shi-Han Chen for providing us with data on the CGG repeat distribution in the Asian population. The OxE18 probe was kindly provided by Professor Kay E Davies. We thank Dr Niels Illum and Dr Susanne Blichfelt for providing clinical information and Mads Dahm Johansen for excellent technical assistance. This work was supported by grants from Helsefonden, Statens lægevidenskabelige forskningsråd, the Plasmid Foundation and the Danish Biotechnological Research programme. 


\section{References}

1 Murray A, Youings S, Dennis N et al: Population screening at the FRAXA and FRAXE loci: molecular analyses of boys with learning difficulties and their mothers. Hum Mol Genet 1996; 5: 727-735.

2 Turner G, Webb T, Wake S, Robinson H: Prevalence of fragile X syndrome. Am J Med Genet 1996; 64: 196-197.

3 Oberle I, Rousseau F, Heitz D et al: Instability of a 550-base pair DNA segment and abnormal methylation in fragile X syndrome. Science 1991; 252: 1097-1102.

4 Pieretti M, Zhang FP, Fu YH et al: Absence of expression of the FMR-1 gene in fragile X syndrome. Cell 1991; 66: 817-822.

5 Verkerk AJ, Pieretti M, Sutcliffe JS et al: Identification of a gene (FMR-1) containing a CGG repeat coincident with a breakpoint cluster region exhibiting length variation in fragile X syndrome. Cell 1991; 65: 905-914.

$6 \mathrm{Fu} \mathrm{YH}$, Kuhl DP, Pizzuti A et al: Variation of the CGG repeat at the fragile $\mathrm{X}$ site results in genetic instability: resolution of the Sherman paradox. Cell 1991; 67: 1047-1058.

7 Chiurazzi P, Macpherson J, Sherman S, Neri G: Significance of linkage disequilibrium between the fragile $\mathrm{X}$ locus and its flanking markers. Am J Med Genet 1996; 64: 203-208.

8 Kunst CB, Warren ST: Cryptic and polar variation of the fragile $\mathrm{X}$ repeat could result in predisposing normal alleles. Cell 1994; 77: 853-861.

9 Kunst CB, Leeflang EP, Iber JC, Arnheim N, Warren ST: The effect of FMR1 CGG repeat interruptions on mutation frequency as measured by sperm typing. J Med Genet 1997; 34: 627-631.

10 Murray A, Macpherson JN, Pound MC et al: The role of size, sequence and haplotype in the stability of FRAXA and FRAXE alleles during transmission. Hum Mol Genet 1997; 6: 173-184.

11 Nolin SL, Lewis FA 3rd, Ye LL et al: Familial transmission of the FMR1 CGG repeat. Am J Hum Genet 1996; 59: 1252-1261.

12 Eichler EE, Holden JJ, Popovich BW et al: Length of uninterrupted CGG repeats determines instability in the FMR1 gene. Nat Genet 1994; 8: 88-94.

13 Eichler EE, Nelson DL: Genetic variation and evolutionary stability of the FMR1 CGG repeat in six closed human populations. Am J Med Genet 1996; 64: 220-225.

14 Kunst CB, Zerylnick C, Karickhoff L et al: FMR1 in global populations. Am J Hum Genet 1996; 58: 513-522.

15 Cavalli-Sforza LL, Piazza A, Menozzi P: History and Geography of Human Genes. Princeton University Press: Princeton, 1994.

16 Larsen LA, Grønskov K, Nørgaard-Pedersen B, Brøndum-Nielsen K, Hasholt L, Vuust J: High-throughput analysis of fragile $\mathrm{X}(\mathrm{CGG}) \mathrm{n}$ alleles in the normal and premutation range by PCR amplification and automated capillary electrophoresis. Hum Genet 1997; 100: 564-568.

17 Richards RI, Holman K, Kozman H et al: Fragile X syndrome: genetic localisation by linkage mapping of two microsatellite repeats FRAXAC1 and FRAXAC2 which immediately flank the fragile site. J Med Genet 1991; 28: 818-823.
18 Grønskov K, Hjalgrim H, Bjerager MO, BrøndumNielsen K: Deletion of all CGG repeats plus flanking sequences in FMR1 does not abolish gene expression. Am J Hum Genet 1997; 61: 961-967.

19 Biancalana V, Taine L, Bouix JC et al: Expansion and methylation status at FRAXE can be detected on EcoRI blots used for FRAXA diagnosis: analysis of four FRAXE families with mild mental retardation in males. Am J Hum Genet 1996; 59: 847-854.

20 Chen SH, Schoof JM, Buroker NE, Scott CR: The identification of a (CGG)6AGG insertion within the CGG repeat of the FMR1 gene in Asians. Hum Genet 1997; 99 793-795.

21 Richards RI, Kondo I, Holman K et al: Haplotype analysis at the FRAXA locus in the Japanese population. Am J Med Genet 1994; 51: 412-416.

22 Zhong N, Liu X, Gou S et al: Distribution of FMR-1 and associated microsatellite alleles in a normal Chinese population. Am J Med Genet 1994; 51: 417-422.

23 Hirst MC, Arinami T, Laird CD: Sequence analysis of long FMR1 arrays in the Japanese population: insights into the generation of long (CGG)n tracts. Hum Genet 1997; 101: 214-218.

24 Grønskov K, Hallberg A, Brøndum-Nielsen K: Mutational analysis of the FMR1 gene in 118 mentally retarded males suspected of fragile $\mathrm{X}$ syndrome: absence of prevalent mutations. Hum Genet 1998; 102: 440-445.

25 Persson I: Anthrolopical investigations of the population of Greenland. Meddr Groenland 1970; 180: 1-78.

26 Gerdes LU, Gerdes C, Hansen PS, Klausen IC, Faergeman $\mathrm{O}$, Dyerberg $\mathrm{J}$ : The apolipoprotein $\mathrm{E}$ polymorphism in Greenland Inuit in its global perspective. Hum Genet 1996; 98: 546-550.

27 Harvald B: Genetic epidemiology of Greenland. Clin Genet 1989; 36: 364-367.

28 Greenberg JH, Turner CG, Zegura SL: The settlement of the Americas: A comparison of the linguistic, dental and genetic evidence. Curr Anthropol 1986; 27: 477-498.

29 Wallace DC, Torroni A: American Indian prehistory as written in the mitochondrial DNA: a review. Hum Biol 1992; 64: 403-416.

30 Arinami T, Asano M, Kobayashi K, Yanagi H, Hamaguchi $\mathrm{H}$ : Data on the CGG repeat at the fragile X site in the non-retarded Japanese population and family suggest the presence of a subgroup of normal alleles predisposing to mutate. Hum Genet 1993; 92: 431-436.

31 Arinami T, Kondo I, Nakajima S: Frequency of the fragile $\mathrm{X}$ syndrome in Japanese mentally retarded males. Hum Genet 1986; 73: 309-312.

32 Vianna Morgante AM, Costa SS, Pares AS, Verreschi IT: FRAXA premutation associated with premature ovarian failure. Am J Med Genet 1996; 64: 373-375.

33 Schwartz CE, Dean J, Howard Peebles PN et al: Obstetrical and gynecological complications in fragile $\mathrm{X}$ carriers: a multicenter study. Am J Med Genet 1994; 51: 400-402.

34 Macpherson JN, Bullman H, Youings SA, Jacobs PA: Insert size and flanking haplotype in fragile $X$ and normal populations: possible multiple origins for the fragile $\mathrm{X}$ mutation. Hum Mol Genet 1994; 3: 399-405. 